\title{
A TV que crianças e adolescentes fariam, se tivessem uma
}

câmara na mão...

\section{A TV que crianças e adolescentes fariam, se tivessem uma câmara na mão...}

\section{Vânia Lúcia Quintão Carneiro}

Professora da Faculdade de Educação da Universidade de Brasilia/UnB E-mail: vania@unb.br

\section{Resumo}

Esta pesquisa investiga as percepções de (424) crianças e adolescentes sobre a programação que assistem e sobre o que produziriam para TV se tivessem uma câmara na mão. A coleta dos dados se realizou em 12 (doze) escolas públicas do Distrito Federal, freqüentadas por estudantes de médio e baixo poder aquisitivo. Um questionário foi aplicado aos estudante, que também elaboraram individualmente um roteiro audiovisual (tipo storyboard). A elaboração do roteiro pelas crianças e adolescentes se deu a partir da questão: que programa de TV fariam se tivessem uma câmara na mão? Este trabalho apresenta as análises das respostas das crianças e dos adolescentes a essa questão, bem como às outras perguntas do questionário, o que permitiu observar qual a relação que elẹs mantêm com a televisão e quais roteiros de programas de TV que eles gostariam de ver em exibição nos canais abertos.

Palavras-chave: Crianças, adolescentes e Televisão, Tv de qualidade; participação de crianças e adolescentes, linguagem audiovisual na escola; leitura crítica e criativa; programação para criança e adolescentes, TV e educação

Introdução

Em "Alagados", Herbert Viana (2000) escreveu: "A esperança não vem do mar, vem das antenas de TV...". Pela televisão, os brasileiros se divertem, se informam, constroem percepções de mundo, dão sentido à existência, criam laços sociais, se reconhecem, aprendem a consumir. A TV impregna o cotidiano e o imaginário de crianças e adolescentes com narrativas fictícias ou reais, de alegrias e dramas, esperanças, medo, sonhos, cenas triviais, personagens comuns, super-heróis.

Em todo o mundo, a televisão sociabiliza gerações. Crianças e adolescentes brasileiros, sobretudo pobres e sem acesso a outras mídias, têm na TV aberta sua única programação. A qualidade dessa programação gratuita e a quantidade de horas diárias que crianças dedicam a consumi-la têm preocupado educadores, pais, comunicadores, pesquisadores e até autoridades governamentais.
Como cobrar a responsabilidade social das emissoras? - Não há lei que regulamente funções educativas, culturais e informativas, de promoção e defesa dos direitos cidadãos, como prevê a Constituição do Brasil (1988). Evidencia-se a necessidade de o governo federal assumir a responsabilidade política de transformar princípios constitucionais em lei e normalizar as atividades dos meios de comunicação eletrônica.

Apesar de bem vigorar no Brasil o "Estatuto da Criança e do Adolescente" (ECA), que pode coibir abusos na TV, como ir além da concepção de qualidade limitada a contrapor-se à "baixaria" e dirigi-la aos interesses específicos de crianças e adolescentes?

A Agência de Notícias dos Direitos da Infância (ANDI) realizou a pesquisa "Remoto Controle", que revela espaços na mídia em que há preocupação em se respeitar os direitos fundamentais dessas audiências. Esses espaços situam-se na programação destinada 
especificamente às audiências jovens, como nos programas de TV para adolescentes, mas constata haver muito a avançar em direção aos direitos de comunicação assegurados pelo ECA e por tratados internacionais sobre os Direitos da Criança. Tais avanços passam pela regulação da mídia e pela participação e formação dos jovens(Vivarta:2004).

$\mathrm{O}$ presente trabalho discute a produção de televisão de qualidade para crianças e adolescentes. Considera que crianças e adolescentes são consumidores, cidadãos, aprendizes, protagonistas sociais, com diferentes níveis de competência e autonomia, com capacidade para expressar pensamentos, emoções, interesses, visões de mundo. São sujeitos sociais, ativos, constituintes de audiências, e não de um conjunto homogêneo (Roche:2000).

Analisa as percepções de adolescentes e crianças sobre programas a que assistem na TV aberta, de quais gostam (ou não) e sobre o que propuseram quando solicitados a manifestarem-se imaginariamente, como se fossem produtores culturais sem restrições.

Os dados foram obtidos de uma investigação com 424 crianças e adolescentes de 12 escolas públicas do Distrito Federal, e que preponderantemente assistem à tevê aberta. As crianças e adolescentes responderam a um questionário $\mathrm{e}$ $60 \%$ entregaram roteiros criados a partir da pergunta: "Que programa de TV você faria se tivesse uma câmara na mão?".

Vale ressaltar que, pela percepção, os "sujeitos-audiência definem a seus modos os sentidos dos diversos programas televisivos, ainda que contradizendo os sentidos outorgados por produtores e emissores" (Orozco, 2001:51).

Este trabalho espera contribuir para a reflexão sobre as questões: o que é TV de qualidade, na percepção de crianças e adolescentes?
Audiências jovens e infantis têm competência para sugerir programações diferentes das que assistem? Criariam programas específicos? Mostrar-se-iam como audiências distintas das adultas?

Qualidade de programação e participação

Entende-se que a qualidade de programação de televisão para crianças e jovens vincula-se à participação dessas audiências como atores sociais, sujeitos em formação, com voz própria, imagens, histórias, interesses, dificuldades, emoções, idéias, opiniões.

Se as crianças forem escutadas, os produtores, conhecendo-lhes melhor suas necessidades, preferências, e os universos, poderão oferecer-lhes programações que atendam a expectativas e a interesses de diversão e aprendizagem sobre si e sobre o mundo, que provoquem respostas críticas e criativas (Carmona:2002). Um exemplo é o programa Castelo Rá-Tim-Bum (TV Cultura-SP), que instaura uma aproximação afetiva, emocional, sensível, estabelece cumplicidades e solicita da criança uma posição ativa e crítica (Carneiro: 1999).

Nos programas para adolescentes, a participação destes poderá evitar as representações estereotipadas dos universos jovens, avançar linguagens, formatos, assegurar multiplicidade de opiniões, problematizar questões adolescentes (Vivarta:2004). Com seu envolvimento, os jovens exercitarão o direito de "influenciar, compartilhar o controle e a responsabilidade de decisões, planos e recursos que os afetam" (ONU:2004). A importância da participação juvenil na sociedade se destacou desde 1985, ano internacional de juventude, participação, desenvolvimento e paz. Reconhece-se que as gerações mais jovens são seres com direito a exercer a cidadania. Preconizam-se direitos ao 
exercício da liberdade de opinião sobre o que lhes diz respeito e à liberdade de expressão e de informação correspondentes à maturidade e à faixa etária.

Portanto, participação não é modismo. No dizer de Pinto (2003): "Trata-se do reconhecimento de que, no centro da acção educativa, como da prática comunicativa, está o sujeito. Tal orientação convoca os media a assumir as suas responsabilidades face à sociedade $\mathrm{e}$ convoca igualmente os mais novos e os mais crescidos a valorizar práticas de expressão e de participação, verdadeiros requisitos de uma cidadania activa e esclarecida".

0 desejo de ser produtor e a estratégia metodológica

O objetivo principal deste trabalho é analisar as percepções de crianças e adolescentes sobre as programações de tevê a que assistem, como também sobre o que produziriam se tivessem uma câmara na mão.

Pressupõe-se que crianças e adolescentes querem ser autores e produtores de mensagens audiovisuais e desenvolver competências para expressar seus mundos e intenções, emoções, imagens, vozes. Situa-se numa perspectiva educativa e investigativa sobre condições, estratégias, propostas que possibilitem a apropriação de linguagens audiovisuais por crianças e adolescentes, como instrumento de expressão e de análise crítica e criativa da TV (Carneiro:1987: 2000:2005).

Acredita-se que a experiência cotidiana com a televisão contribui para estimular os poderes imaginativos das crianças. De acordo com Gardner (1999:218), as evidências disso estariam nas reencenações de episódios de programas preferidos e que ficariam mais evidentes se a criança pudesse

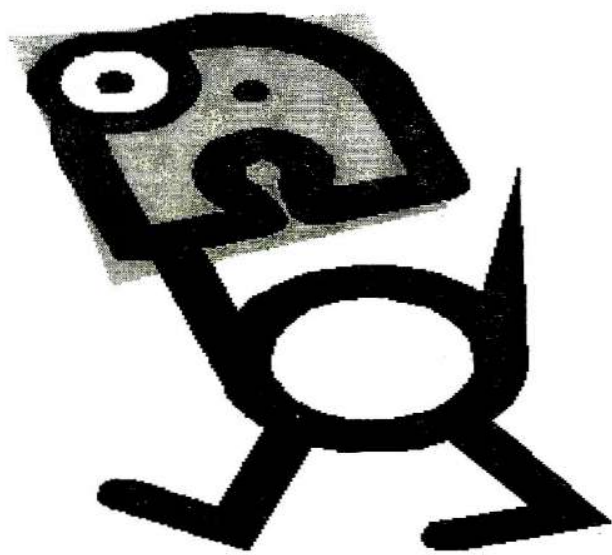

atuar como diretora de televisão. Supõe que a principal habilidade criativa inculcada pela TV seja a do planejar e roteirizar cenas dramáticas.

Fiske (1989:73) acrescenta a presentatividade da tevê como um convite à adoção da postura à maneira do produtor. Relata caso de espectador que escreve roteiros utilizando conhecimento dos códigos e estruturas de uma novela semelhante ao processo profissional de escrita de um roteiro - pelo prazer de comparar suas previsões às do episódio da novela exibido na TV.

Lazar (1985:75) também vê na imitação de cenas inspiração criadora: "A televisão incita-as a representar as cenas, o que não significa repetição, mas sim uma espécie de inspiração proveniente de uma cena ou de uma seqüênciä. Isto significa que a televisão desencadeia atividades criadoras em crianças".

Dessa perspectiva, a opção de utilizar uma situação imaginária de produção de programas a partir $d a$ hipótese fantástica de uma câmara à mão constituiu-se numa estratégia metodológica para captar manifestação espontânea de idéias, emoções, dúvidas, dos conheci-mentos e desejos dos sujeitos desta pesquisa em relação à televisão.

Além de elaborarem pequenos roteiros audiovisuais, os sujeitos também responderam a questionários (semi-abertos) para complementaram 
as informações necessárias à compreensão sobre eles e suas relações com a televisão, em seus contextos específicos. A pesquisa se realizou em duas etapas: em 2000 , com 184 participantes; e em 20042005 , com 240 . Houve a participação de estudantes do curso de Pedagogia da Universidade de Brasília e bolsistas do programa de iniciação científica PIBIC (CNPq) e do Decanato de Extensão da UnB.

Horários de ver televisão e interlocutores

Dos 424 sujeitos (6 a 21 anos) da pesquisa, $69 \%$ são crianças de 6 a 12 anos e $32 \%$ são jovens ou adolescentes (embora o Estatuto da Criança e do Adolescente situe a adolescência entre 12 e 18 anos incompletos).

$\begin{array}{lll}\text { IDADES } & \text { Sujeitos } & \% \\ 6-9 & 127 & 30 \\ 9-12 & 156 & 37 \\ 12-17 & 99 & 23 \\ 18-21 & 34 & 8 \\ \text { Sem especificar } & 8 & 2 \\ \text { Total } & 424 & \end{array}$

A tevê continua onipresente na vida das crianças. O horário de assistir televisão, para crianças, é todo aquele em que não se está na escola: manhã, tarde ou noite-nunca inferior a $3 \mathrm{~h} 30 \mathrm{~min} / \mathrm{dia}$ embora circunstancialmente haja concorrência de alguma outra atividade ou controle dos pais, a depender do nível socioeconômico. Adolescentes vêem mais tevê à noite.

A noite é horário nobre, a que a família assiste com mais intensidade. $\mathrm{Na}$ TV aberta, prevalecem telejornais, novelas, filmes, entretenimento adulto. Geralmente, crianças, adolescentes e adultos assistem a um mesmo programa. Daí decorre que na medição de audiência os programas adultos são os mais vistos por crianças. Embora crianças gostem muito de programas sobre o mundo adulto, não significa que esses sejam os seus preferidos. Além disso, $55 \%$ das famílias questionadas têm em casa um único televisor. Acrescente-se também que não há programações específicas para essas faixas etárias à noite, na TV aberta. Ressalte-se que o infantil Castelo Rá-Tim-Bum, experimen-talmente lançado em horário nobre, chegou ao $3^{\circ}$ lugar de audiência em São Paulo (Carneiro:1997).

As crianças têm na família seus primeiros interlocutores sobre o programa de TV a que assistem e continuam esse processo de recepção nas conversas com amigos e colegas. Professores também aparecem como interlocutores, mas em menor proporção. Adolescentes dão visível preferência à interlocução com seus amigos, que constituem seu grupo, tribo. A recepção, como define Orozco (2001:23), é interação com múltiplas mediações, contextualizada material, cognitiva e emocionalmente, e que se prolonga em processo complexo por vários cenários.

Programas preferidos: elogios e críticas de desenhos a informativos

As preferências das crianças recaem na programação infantil específica. Em primeiro lugar, os desenhos $(40 \%)$, geralmente inseridos em programa infantil, com apresentador. Em segundo lugar, vêm as novelas $(20 \%)$. Adolescentes optam primeiro por telejornais (22\%) $\mathrm{e}$, secundariamente, por novelas (16\%). Apesar das novelas ocuparem o segundo lugar para ambos, são grandes as diferenças entre crianças e adolescentes.

Programas preferidos pelas crianças

$\begin{array}{ll}\text { Desenho } & 40 \% \\ \text { Novela } & 20 \% \\ \text { Programa Infantil } & 16 \% \\ \text { Humor } & 11 \%\end{array}$




$\begin{array}{ll}\text { Filmes } & 6 \% \\ \text { Esporte } & 2 \% \\ \text { Jornal } & 2 \% \\ \text { Outros } & 3 \%\end{array}$

Programas preferidos pelos adolescentes

$\begin{array}{ll}\text { Jornal } & 22 \% \\ \text { Novela } & 16 \% \\ \text { Revista Eletrônica } & 10 \% \\ \text { Reportagens } & 6 \% \\ \text { Filmes } & 8 \% \\ \text { Seriados } & 7 \% \\ \text { Programa de Auditório } & 3 \% \\ \text { Esporte } & 8 \% \\ \text { Desenho } & 9 \% \\ \text { Programa de Humor } & 5 \% \\ \text { Outros } & 6 \%\end{array}$

Nem crianças nem adolescentes constituem grupos homogêneos. Para Buckingham (2005:21-22), não se pode falar de crianças como categoria homogênea. $\mathrm{O}$ significado e o modo de viver a infância dependem de vários fatores, como classe social, gênero, etnia.

Observa-se que as crianças a partir dos 10 anos continuam a preferir desenhos - como as mais novas -, mas não se consideram crianças. Criticam os desenhos e são, geralmente, implacáveis com os apresentadores. Não gostam de ser vistas como crianças: "Ai ela fala, não sei o que os baixinhos... E me dá raiva. É ridiculo". Contradizemse. A apresentadora adulta é criticada por ser infantil, e, ao mesmo tempo, a criança reclama de apresentadores que não sabem ser infantis: "Querem ser crianças, mas não têm estímulo para ser, deveriam assumir o lado criança" (Ítalo - 11anos). Demonstram preocupar-se com a função educativa dos programas infantis, especialmente para "crianças mais novas", embora reclamem da Xuxa, que deseduca as crianças, e abominem a bruxa Keka. " $A$ Keka atrapalha a educação das crianças. Ela come meleca, ensina coisas erradas" (Maria Eduarda - 10 anos).
"Uma vez vi ela ensinando a chutar os cachorros. A bruxa Keka é o pior do programa" (Wadson - 12). Luma, de 10 anos, pondera sobre a distinção entre o personagem Keka e a atriz que a representa: "Se as crianças enxergarem a Keka (personagem) como a Xuxa (apresentadora), elas vão fazer o que a Keka fala. Se virem a Keka como uma bruxa má, não vão seguir o que ela fala". Gabriela (10 anos) sugere trocar apresentadores: "Acho que eles não apresentam bem, tem que colocar alguém menor, eles são muito grandes". Eduardo, de 10 anos, propõe: "Eu tiraria a Xuxa da $T V$, mas deixaria alguns desenhos". Crianças entre 10 e 12 anos parecem preferir desenhos exibidos nos programas infantis, como Marcela (10 anos): "Não gosto do Bom Dia, nem do TV Xuxa, só de alguns desenhos; os apresen-tadores são todos bregas".

Várias crianças, entretanto, afirmam gostar dos apresentadores, principalmente as mais novas. $\mathrm{Na}$ lista do que não gostam no programa preferido, aparecem alguns desenhos e apresentadores, o que demonstra a importância do 'perfil e do papel do apresentador nos programas infantis.

Conforme o observado, na pesquisa Remoto Controle, sobre a programação para jovens, a qualidade dos programas depende muito do apresentador. Ele é o mediador, o animador, o interlocutor central que pode provocar espelhamento e identificação com o telespectador (Vivarta, 2003:198).

$\mathrm{Na}$ categoria programa infantil, as crianças incluem o Sítio do PicaPau Amarelo, que não tem desenhos, mas exibe programas com desenhos. Vale salientar que, em 2000, os resultados da pesquisa mostravam uma oferta maior de programação para crianças. Incluía até uma novela infantil (Chiquititas). $\mathrm{Na}$ preferência das crianças, os desenhos continuaram em primeiro lugar, mas os programas infantis assumiram o 
segundo lugar, que antes era das novelas, o que demonstra que novelas adultas poderão aparecer em terceiro lugar, se o público infanto-juvenil tiver mais opções de programas em sua faixa etária.

Lazar (1985) observa que, na idade de 10 a 12 anos, a criança tornase uma espectadora capaz de discernir e criticar acontecimentos. Já não aceita facilmente os julgamentos dos outros; contesta, põe em causa, analisa.

Nas crianças dessa faixa, dá-se a diferença de gênero: a preferência maior dos meninos é por programas esportivos e filmes de ação; meninas preferem o seriado para adolescentes "Malhação" (no formato novela), seguido das novelas adultas. Constata-se um início de interesse por telejornais, programas preferidos por adolescentes $(22 \%)$, enquanto os desenhos caem para 9.\%. A preferência de crianças por desenhos e de adolescentes por telejornais explica-se pela necessidade que as primeiras sentem, segundo Hodge e Tripp (1992:216), de fantasia, como há em desenhos animados. Os adolescentes requerem programas que os aproximem mais da realidade. Vilches (1993:73) considera que a narrativa de uma notícia tem grande função de aprendizagem, não importa se transformada de realista em fantástica.

\section{0 não-à-violência}

Embora haja muitas diferenças entre crianças e adolescentes, há convergência de interesses na preferência, em segundo lugar, por telenovelas e no repúdio à violência como o mais abominável aspecto da programação. Chamam a atenção menções de crianças a casos de violência, além dos mais temidos (armas e crimes): terror, criança apanhando, brigas, choro, notícias ruins. Há desagrado quando seu clube de futebol perde um jogo, o personagem preferido não vence, o programa preferido termina, é hora do intervalo comercial, a tevê repete um programa ou quando há monotonia ou pornografia no ar.

$\mathrm{O}$ medo das crianças ante a violência pode ser explicado por serem elas, potencialmente, as mais fáceis vítimas de crime (Buckingham: 2005; Feilitzen:2002). Feilitzen destaca que as imagens recorrentes de crianças e jovens nos noticiários midiáticos sobre violência e crime apresentam-nas como vítimas, sofrendo abuso psíquico, sexual, físico. À parte que nos relatos de violência predomina na mídia o objetivo sensacionalista.

A tv que estaria no ar: alegria e aprendizagem

Ao primeiro olhar, pode-se pensar ser a televisão atual. Os programas propostos pelas crianças e pelos adolescentes parecem conservar idênticos formatos e temáticas, mas as diferenças são muitas e sutis. Não é uma televisão qualquer. Há diversidade de programação e abordagens dirigidas a novas audiências. A oferta parte das preferências próprias de crianças e adolescentes, observadas na programação a que assistem. As crianças propõem desenhos ( $1^{\circ}$ lugar), novelas $\left(2^{\circ}\right)$, programas infantis $\left(3^{\circ}\right)$, filmes $\left(4^{\circ}\right)$; seguem-se clipes, programas de humor. Adolescentes enfatizam infor-mativos (jornais, reportagens, documentários, educativos) seguido por filmes, seriados, música e programas de humor.

As novelas propostas pelas crianças podem apresentar redução da intensidade dramática. As crianças têm contempladas suas necessidades específicas de desenvolvimento emocional, afetivo, enquanto os adultos continuam a se entreter com abordagens dramáticas mais intensas. $\mathrm{O}$ aconchego de assistir uma novela 
em família é preservado. Como propõe Janaína (8 anos):

Eu filmaria uma novela. Essa novela seria de criança de qualquer idade, mas para crianças, como Chiquititas, $e$ Laços de Familia para adultos e novelas legais. Para criança tem de ser normal, sem coisa romântica, triste, emocionante. Para adultos, uma coisa romântica, triste, emocionante. Todas crianças poderiam assistir novela e adultos e familia inteira".

Embora a presença da temática da violência seja repudiada, ela aparece na nova programação das crianças e dos adolescentes. Mas há que se observar que a violência aparece agora como forma de "luta" em roteiros de meninos. Na proposta dos adolescentes, o roteiro de um crime não se encerra com o crime, mas com uma questão sobre ele.

As crianças distinguem "luta" de "briga", esta condenada por todos. A análise revela que as crianças-autoras não consideram luta como violência, mas como jogo que podem controlar, arte, "uma briga simulada". Luta não amedronta. Crime, sim.

Os adolescentes-autores que abordam notícias sobre crimes contra jovens esclarecem, nas perguntas com que concluem os informativos propostos, ser saudável discutir, buscar o entendimento do que aconteceu, não se deixar amedrontar. Crianças e adolescentes parecem fazer clara distinção entre violência factual e ficcional. Pesquisadores argumentam que a violência que mais angustia crianças é a real, com formas realistas, imagens fotográficas (Gardner:1999; Vilches:1993; Hodge e Tripp:1992).

$\mathrm{Na}$ nova programação, conseqüentemente, violência deixa de ser espetáculo, é contextualmente discutida. Perde espaço para o riso e a alegria. São variadas situações e

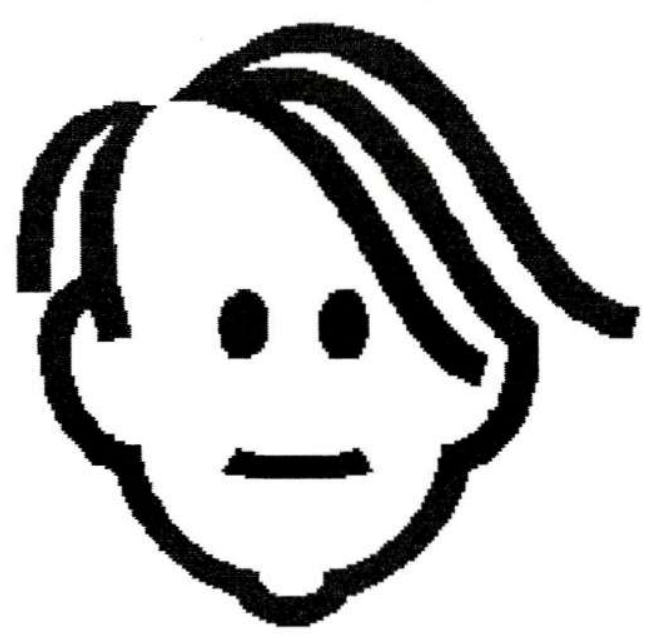

histórias para provocar riso, ainda que sem motivo aparente, que crianças (principalmente) e adolescentes sugerem para nova programação. Fazem lembrar do riso alegre que, para Propp (1992:163), pode ser causa e origem de pretextos insignificantes, mas é de importância vital por "eliminar qualquer emoção negativa e torná-la muito útil e necessária socialmente, porque desperta a alegria de viver, cria o bom humor e com isso eleva a tônus da vida". Há proposta de rir até chorar: "Que todos que assistissem pudessem rir e chorar ao mesmo tempo" (Elaine - 11 anos).

A essência dos programas está nas experiências diárias, nas brincadeiras com parentes ou amigos em casa, com animais, amigos, escolas, igreja, cenários imaginários. A tevê integra esse cotidiano como tela que se alimenta do dia-a-dia e na qual crianças e adolescentes se querem ver como atores, com suas próprias imagens e vozes contracenando com familiares e companheiros desse seu entorno, não isentos dos conflitos cotidianos. Família é tema recorrente nos roteiros das crianças. São comuns as cenas em que apenas a mãe ou o pai está presente. As crianças menores 
apreciam representar a família por seqüência de planos gerais de uma criança de mãos dadas com pai e mãe, de uma casa, de um primeiro plano da criança e outro de animal de estimação ou de uma flor. No interior da casa, destaca-se um televisor e desenrolam-se os conflitos das histórias. Acontece desde uma disputa do controle remoto da TV, que expõe várias divergências, até uma falta de atenção dos pais: $O$ pai cansado dormiu sem filmar a filhae a filha cansada dormiu sem fazer o programa de televisão. Observa-se que todas as dificuldades são superadas no final. Mas ninguém está imune a elas. Personagens famosos e poderosos também aparecem enfrentando dificuldades, tais como o melhor time brasileiro para vencer um adversário internacional, o boxeador brasileiro campeão mundial em uma luta.

Há demanda e satisfação de crianças, inclusive de préadolescentes, por programas de entretenimento que lhes ajudem, afetivamente, socialmente, emocionalmente, a enfrentar conflitos, o que desafia emissoras de TV a oferecerem aprendizagem e diversão (Carneiro, 1999; Roche: 2000).

O meio ambiente é tema que perpassa diferentes formatos e suas abordagens demonstram sensibilização das crianças e dos adolescentes em vários níveis. Para crianças, a natureza é geralmente cenário de histórias, convoca a admiração e a proteção de florestas e animais. Adolescentes acrescentam a preocupação maior de denunciar crimes ambientais, conhecer melhor o meio, os rios, a fauna e a flora, a modernidade do desenvolvimento sustentável, discutir e refletir. De um modo geral, as narrativas dos adolescentes não se preocupam em oferecer soluções reconfortantes, e sim provocar discussões, reflexões. Há uma adolescente que engravida sem querer. Há relatos de brigas - entre grupos rivais - que não terminam bem. A droga é abordada a partir de da história de "entrar no mundo errado e morrer".

À parte os temas graves, a programação juvenil não deixa de ser diversão. Há descontração ("agitos"), shows de bandas, esportes radicais, humor. Da sensação do primeiro beijo pode-se criar uma fantástica história de morcegos. Chamam a atenção informativos sobre "ciências, história e muito mais", que despertam "as curiosidades dos mundos", de culturas como a chinesa, artes marciais, danças de dragões, questões econômicas, políticas, sociais.

Por estarem no ensino médio e prestarem avaliações anuais visando à universidade, é natural preocuparem-se em relacionar tevê com escola, articularem entretenimento a conhecimento: "Um programa para jovens, partindo do que gostam (esportes radicais), mostra temas ligados ao que estudam na escola" (Elisângela - 18 anos). Ressaltam programas envolventes, que incentivem os jovens ao estudo e mostrem temas que trabalham em sala. Atribuem sentidos distintos à instituição escolar e à televisão, sem oposição. Desafiam a articulação entre o entretenimento e os interesses escolares dos estudantes.

Pesquisa internacional da Unesco (2003), feita com 17 milhões de sujeitos, revela que a maioria dos estudantes tem dificuldade de se interessar pelo que se diz em sala de aula, o que sugere que a escola valoriza as aprendizagens midiáticas extraclasse. Paulo Freire crê que a escola educaria melhor se conhecesse as vivências das crianças e utilizasse instrumentos que lhes despertassem interesse pelo saber:

A escola trabalharia melhor
se usasse instrumentos que
ajudassem os estudantes a
exercitar a curiosidade pelo
saber, conhecendo as 
experiências estudantis extraescolares: 'o que fazem, como fazem, como brincam, como trabalham' e com esses instrumentos aguçar a curiosidade e a possibilidade de crianças conhecerem melhor o que conhecem e conhecerem de forma sistematizada o que não conhecem (Freire, 1983, 44).

\section{Conclusão}

Ao imaginarem que têm à mão condições materiais para realizar mensagens audiovisuais, crianças e adolescentes escrevem histórias, desenham cenas, mostram-se atores, apresentadores, críticos, produtores culturais, autores, bem mais que telespectadores. Participam como sujeitos que opinam, compartilham experiências, histórias e situações de seriedade ou humor, discutem com crianças, adolescentes e adultos. Os níveis em que podem contribuir para a qualidade de um programa apontam para: selecionar temas, discutir suas abordagens, experimentar lingua-gens, serem atores não caricaturais, que têm imagens e vozes próprias, decidem como diretores. A televisão se faz presente nas propostas pelo que representa nos cotidianos deles e pelo que precisam que seja. A escola é aliada para a apropriação das ferramentas com que pensar criticamente tevê e expressar mundos com palavras e imagens.

Se os dirigentes de emissoras abertas brasileiras ouvissem esse pleito franco e o respeitassem, de 2000 a 2005 o horário de programas específicos para audiências de crianças e adolescentes não haveria diminuído. E hoje, no horário da tarde, não estaria sendo reprisada uma novela triste, emocionante $e$ romântica como Laços de Família, exibida em 2000 às 21 horas, para audiência adulta.

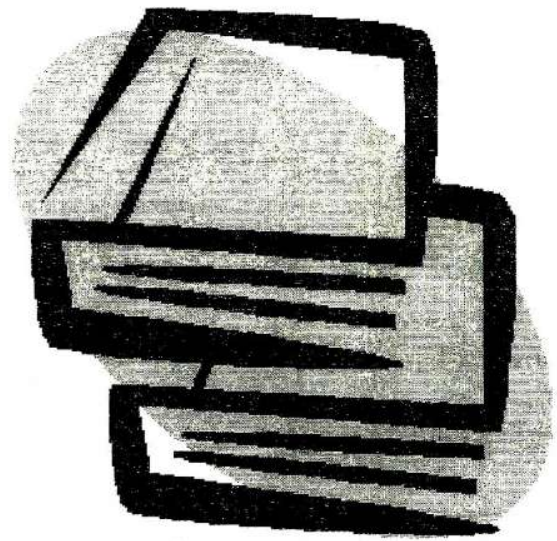

\section{Abstract}

The objective of this research was to investigate the perception of 424 children and teenagers about the programs they watch on $t v$, and what kind of programs they would produce if they had a camera on their hands. The data collection was made in 12 schools of Distrito Federal, attended by students who belong to medium and lower income classes. A questionnaire was presented to the students, who were asked to elaborate individually some audiovisual instructions with drawings (storyboard). The starting point to the elaboration of the instructions by the kids and teens was the question: What tv program would you make if you had a camera on your hands? This paper presents the analysis of the answers of the children and teenagers about the question above, as well as the other questions in the questionnaire, so that it was possible to observe which kind of relation they have with the television and which tv storyboards they would like to watch in the open channels.

Keywords: quality TV; children, adolescents and TV; participation of children and adolescents; programs for kids and teens, TV and education; audiovisual production in school; critical and creative reading.

\section{Referência}

BUCKINGHAM, David. Media education: literacy, learning and contemporary cultura. London, Polity, 2005. 


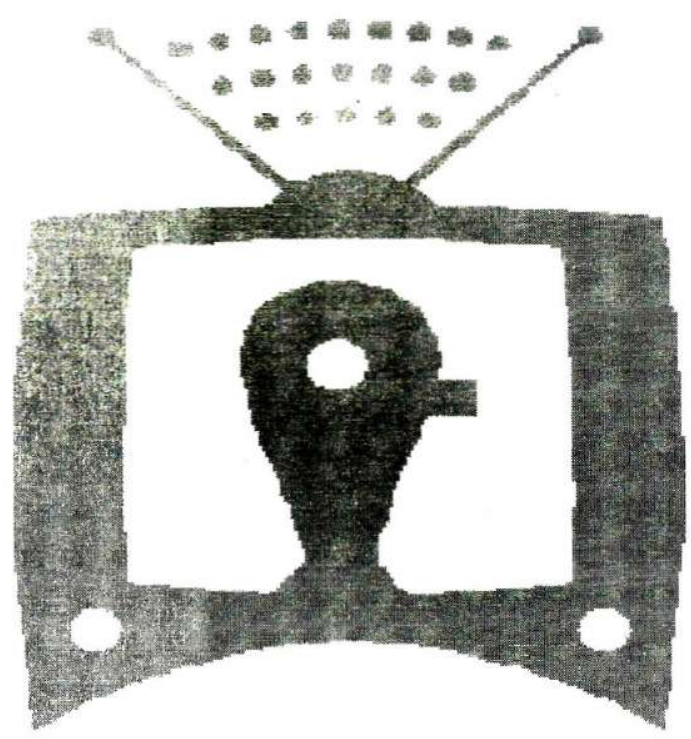

BUCKINGHAM, David. A posição da produção. In: FEILITZEN, Cecília Von; CARLSSON, Ulla (orgs.) A criança e a mídia: imagem, educação, participação. São Paulo, Cortez, 2002.

CARMONA, Beth. A participação da criança na televisão Brasileira. IN: FELITIZEN, Cecília Von; CARLSSON, Ulla ( orgs.). A criança e a mídia. São Paulo: Cortez; Brasília, DF: UNESCO, 2002 p 331- 6.

CARNEIRO, V. L. Quintão. Castelo RáTim-Bum: educativo como entretenimento. São Paulo. Annablume, 1999.

CARNEIRO, V. L. Quintão. Um desafio da TV na escola: o expressar-se com linguagem audiovisual para melhor analisar a TV e educar hoje. Relatório de pesquisa. Brasília, FE- UNB, 2005.

CARNEIRO, V. L. Quintão. Criança produtora audiovisual: expressando o mundo e o da TV. Relatório de pesquisa e extensão. Brasília, Decanato de extensão, UnB, 2000.

CARNEIRO, V. L. Quintão. Uma aventura pedagógica : do desejo de fazer cineminha à produção de suas próprias mensagens. Natal, 1987. UFRN, Dissertação de mestrado, Faculdade de Educação- UFRN.

FISKE, J. Television Culture. London/ New York, Routledge, 1989.

FREIRE, P.; GUIMARÃES, S. Sobre eduçação: diálogos- Volume II - RJ, Paz e Terra, 1984.
GARDNER, Howard. Arte, mente e cérebro - Uma abordagem cognitiva da criatividade. PortoAlegre:Artes Médicas Sul, 1999.

HODGE, Bob e TRIPP, David. Children and television: a semiotic approach. Cambridge: Polity Press, 1992

LAZAR, Judith. École, communication, televisión. Paris, Presses Universitaires de France, 1985.

VIVARTA, Veet (coord.) Remoto Controle: linguagem, conteúdo e participação nos programas de televisão para adolescentes. São Paulo: Cortez, 2004.

FEILITZEN, Cecília Von. Educação para a mídia, participação infantil e democracia. In: FEILITZEN, Cecília Von; CARLSSON, Ulla (orgs.) A criança e a mídia: imagem, educação, participação. São Paulo, Cortez, 2002

OROZCO GÓMES, Guilermo. Televisión, audiencias y educación. Buenos Aires: editorial Norma, 2001

ORGANIZAÇÃO DAS NAÇÕES UNIDAS (ONU). Departamento de Assuntos Econômicos e Sociais. "Um manual para jovens avaliarem a política nacional de juventude. Brasília: 2004. Disponível em: < http://www.onubrasil.org.br/ > . Acesso em: 20 junho 2005.

PROPP, Vladimir. Comicidade e Riso. São Paulo: Atica, 1992.

PINTO, Manuel. A educação para os media, uma aposta com futuro. Huelva: Congreso Ibero americano de Comunicación y Educación 'Luces en el laberinto audiovisual", out.2003

ROCHE, Maritza López de la; MARTIN-BARBERO, Jesús; RUEDA, Amanda. Los niños como audiencias. Santafé de Bogotá, Vinci, 2000.

UNESCO. Educação Hoje. jan/mar., $n^{\circ}$ 4, p.5.

VIANA, Herbert. Alagados - Paralamas do Sucesso - 1986. Disponível em:

$<$ http://vagalume.uol.com.br/letra/p/ paralamas-do-sucesso/alagados.html $>$. Acesso em: 10 julho 2000.

VILCLES, L. La television: los efectos del bien y del mal. Barcelona, Paidós, 1993.

Data do Recebimento: 28/09/2005

Data do aceite: 17/10/2005 